\title{
A 12-year study evaluating the outcomes and predictors of mortality in critically ill cancer patients admitted with septic shock
}

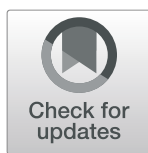

Wedad B. Awad ${ }^{1 *}$, Lama Nazer', Salam Elfarr ${ }^{1}$, Maha Abdullah ${ }^{1}$ and Feras Hawari ${ }^{2}$

\begin{abstract}
Background: Though sepsis is common in patients with cancer, there are limited studies that evaluated sepsis and septic shock in this patient population. The objective of this study was to evaluate the outcomes and to identify predictors of mortality in cancer patients admitted to the intensive care unit (ICU) with septic shock.

Methods: This was a retrospective study conducted at a medical-surgical oncologic ICU of a comprehensive cancer center. Adult cancer patients admitted with septic shock between January 1, 2008 and December 31, 2019 were enrolled. Septic shock was defined as an ICU admission diagnosis of sepsis that required initiating vasopressors within $24 \mathrm{~h}$ of admission. Patient baseline characteristics, ICU length of stay and ICU and hospital mortality were recorded. Univariate analysis and logistic regression were performed to identify predictors associated with ICU and hospital mortality.

Results: During the study period, 1408 patients met the inclusion criteria. The mean age was $56.8 \pm 16.1$ (SD) years and mean Acute Physiology and Chronic Health Evaluation (APACHE) II was 23.0 47.91 (SD). Among the enrolled patients, $67.8 \%$ had solid tumors while the remaining had hematological malignancies. Neutropenia and thrombocytopenia were reported in 19.3 and $39.5 \%$ of the patients, respectively, and mechanical ventilation was required for $42 \%$ of the patients. Positive cultures were reported in 836 (59.4\%) patients, most commonly blood (33\%) and respiratory (26.6\%). Upon admission, about half the patients had acute kidney injury, while elevated total bilirubin and lactic acid levels were reported in 13.8 and $65.2 \%$ of the patients, respectively. The median ICU length of stay was 4 days (IQR 3-8), and ICU and hospital mortality were reported in 688 (48.9\%) and 914 (64.9\%) patients, respectively. Mechanical ventilation, APACHE II, thrombocytopenia, positive cultures, elevated bilirubin and lactic acid levels were significantly associated with both ICU and hospital mortality.
\end{abstract}

Conclusions: In a relatively large cohort of patients with solid and hematological malignancies admitted to the ICU with septic shock, hospital mortality was reported in about two-third of the patients. Mechanical ventilation, APACHE II, thrombocytopenia, positive cultures, elevated bilirubin and lactic acid levels were significant predictors of mortality.

Keywords: Sepsis, Septic shock, Cancer, Oncology, Critical care outcomes, Intensive care units

\footnotetext{
* Correspondence: WA.12503@khcc.jo

'Department of Pharmacy, King Hussein Cancer Center, P.O. Box 1269,

Al-Jubeiha, Amman 11941, Jordan

Full list of author information is available at the end of the article
}

C C The Author(s). 2021 Open Access This article is licensed under a Creative Commons Attribution 4.0 International License, which permits use, sharing, adaptation, distribution and reproduction in any medium or format, as long as you give appropriate credit to the original author(s) and the source, provide a link to the Creative Commons licence, and indicate if changes were made. The images or other third party material in this article are included in the article's Creative Commons. licence, unless indicated otherwise in a credit line to the material. If material is not included in the article's Creative Commons licence and your intended use is not permitted by statutory regulation or exceeds the permitted use, you will need to obtain permission directly from the copyright holder. To view a copy of this licence, visit http://creativecommons.org/licenses/by/4.0/ The Creative Commons Public Domain Dedication waiver (http://creativecommons.org/publicdomain/zero/1.0/) applies to the data made available in this article, unless otherwise stated in a credit line to the data. 


\section{Background}

Sepsis is a common complication in cancer patients due to the immune-suppression associated with the underlying malignancy and the various cancer-related therapies [1]. In a large cohort of over 1 million sepsis hospitalizations in the US, 1 in 5 admissions were cancer-related [2]. Furthermore, in critically ill patients with cancer, sepsis was among the most common admission diagnosis to the intensive care units (ICUs) [3-5]. Though the outcomes of critically ill cancer patients have improved over the years, studies continue to report a higher mortality in cancer patients with sepsis, compared to non-cancer patients [2, 6-11].

Septic shock is a subset of sepsis which involves the initiation of vasopressors to maintain adequate arterial blood pressure, despite fluid resuscitation. The underlying circulatory, metabolic, and cellular abnormalities in septic shock are associated with high hospital mortality, approaching 40-60\% [12].

Though several studies have evaluated sepsis in cancer patients, most did not specifically evaluate the subset of patients with septic shock. In addition, most of the studies included relatively small sample sizes, were conducted over a short period of time, or included a specific subset of cancer patients $[4,5,13-21]$. Therefore, we conducted this study to evaluate the outcomes of cancer patients admitted to the ICU with septic shock and to identify predictors of mortality in this patient population.

\section{Methods}

This was a retrospective study conducted at King Hussein Cancer Center, a 370-bed comprehensive cancer teaching hospital located in Amman, Jordan. The hospital has two medical-surgical oncologic critical care units that serve around 800 patients per year, who are admitted with cancer and non-cancer related critical illnesses. The ICU has a closed-unit model, with the most common admission diagnosis being respiratory failure and sepsis and an overall ICU mortality of 35\% [3]. The study was approved by the institutional review board, with a waiver of informed consent.

The study included adult patients ( $\geq 18$ years) with solid and hematologic malignancies who were admitted to the ICU with septic shock between January 2008 and December 2019. Septic shock was defined as having an admission diagnosis of sepsis along with the initiation of vasopressors within $24 \mathrm{~h}$ of ICU admission.

The pharmacy medication database was used to identify patients who received norepinephrine during the study period. Norepinephrine was the vasopressor we searched for since it is the first line vasopressor used in our patients with septic shock, as per the recommendations of the Surviving Sepsis Campaign guidelines [22].
The patient medical records were reviewed to determine the admission diagnosis of the patients. Patients who received norepinephrine within the first $24 \mathrm{~h}$ of their ICU admission and had an admission diagnosis of sepsis were included. Patients who were started on norepinephrine after $24 \mathrm{~h}$ of their ICU admission and those who were prescribed norepinephrine but the infusion was not initiated, based on the medical notes, were excluded.

Using the electronic patient medical records, the following patient characteristics were recorded: patient demographics, Acute Physiology and Chronic Health Evaluation (APACHE) II score, type of malignancy, chemotherapy received within 1 month of ICU admission, Surveillance Epidemiology and End Results (SEER) stage, smoking history, absolute neutrophil count (ANC) and platelet counts upon ICU admission, the presence of positive cultures, type of microorganisms, ICU length of stay and ICU and hospital mortality. For organ dysfunction; mechanical ventilation, serum creatinine, total bilirubin and lactic acid levels upon ICU admission were recorded. Neutropenia and thrombocytopenia were defined as having ANC of less than 1000 and platelet count of less than $100^{*} 10^{\wedge} 3 / \mathrm{ul}$, respectively. Acute kidney injury was defined as an increase in serum creatinine by $0.3 \mathrm{mg} / \mathrm{dl}$ or more within $48 \mathrm{~h}$. Total bilirubin and lactic acid levels were considered elevated if the level upon ICU admission was equal to or higher than $2.5 \mathrm{mg} / \mathrm{dl}$ and $2 \mathrm{mmol} / \mathrm{l}$, respectively. The data was entered into a de-identified secured data collection sheet.

\section{Statistical analysis}

Continuous data was presented as mean \pm standard deviation (SD) or median and IQR, whereas categorical data was presented as counts and percentages. Univariate analysis using Chi square test or non-parametric Wilcoxon rank test as appropriate was conducted to identify factors associated with ICU and hospital mortality. Factors included in the univariate analysis were: age, gender, APACHE II score, type of malignancy, chemotherapy received within 1 month of ICU admission, SEER stage, smoking history, neutropenia and thrombocytopenia upon ICU admission, acute kidney injury and elevated total bilirubin and lactic acid levels upon ICU admission, need for mechanical ventilation and having positive cultures. Multivariate logistic regression was performed for factors that were significant in the univariate analysis. Statistical significance was considered as a $p$-value $\leq 0.05$. All analyses were performed using SAS version 9.4 (SAS Institute Inc., Cary, NC).

\section{Results}

Over the study period, 1408 patients met the inclusion criteria. Patient demographics and baseline characteristics are outlined in Table 1 . The mean age was $56.8 \pm$ 
Table 1 Baseline characteristics and univariate analysis

\begin{tabular}{|c|c|c|c|c|c|c|c|}
\hline \multirow[t]{2}{*}{ Baseline characteristic } & \multirow{2}{*}{$\begin{array}{l}\text { Value } \\
(N=1408)\end{array}$} & \multicolumn{2}{|c|}{ ICU mortality } & \multirow[t]{2}{*}{ P-value } & \multicolumn{2}{|c|}{ Hospital mortality } & \multirow[t]{2}{*}{$P$-value } \\
\hline & & Alive & Dead & & Alive & Dead & \\
\hline Age (years), mean (SD) & $56.8(16.1)$ & 57.3 & 56.3 & 0.1770 & 56.3 & 57.1 & 0.4132 \\
\hline Apache II Score, mean (SD) & $23.0(7.91)$ & 21.3 & 24.9 & 0.0000 & 20.4 & 24.5 & 0.0000 \\
\hline Male gender, $\mathrm{N}(\%)$ & $821(58.3 \%)$ & $437(60.7 \%)$ & $384(55.8 \%)$ & 0.06336 & 317 (64.2\%) & $504(55.1 \%)$ & 0.00104 \\
\hline Type of malignancy & & & & 0.7762 & & & 0.63671 \\
\hline Hematology, N (\%) & $453(32.2 \%)$ & $229(31.8 \%)$ & $224(32.6 \%)$ & & $163(33.0 \%)$ & $290(31.8 \%)$ & \\
\hline Lymphoma & $191(13.6 \%)$ & & & & & & \\
\hline Leukemia & $188(13.4 \%)$ & & & & & & \\
\hline Multiple Myeloma & $66(4.6 \%)$ & & & & & & \\
\hline Others & $8(0.6 \%)$ & & & & & & \\
\hline Solid, N (\%) & $955(67.8 \%)$ & $491(68.2 \%)$ & 464 67.4\%) & & $331(67.0 \%)$ & $624(68.2 \%)$ & \\
\hline Gastrointestinal Tumors & $248(17.6 \%)$ & & & & & & \\
\hline Breast Cancer & $143(10.2 \%)$ & & & & & & \\
\hline Lung Cancer & $138(9.8 \%)$ & & & & & & \\
\hline Gynecologic Tumors & $69(4.9 \%)$ & & & & & & \\
\hline Bladder Cancer & $60(4.3 \%)$ & & & & & & \\
\hline Prostate Cancer & $43(3.0 \%)$ & & & & & & \\
\hline Pancreatic Cancer & $34(2.4 \%)$ & & & & & & \\
\hline Renal Cell Carcinoma & $31(2.2 \%)$ & & & & & & \\
\hline Others & $176(12.5 \%)$ & & & & & & \\
\hline Unknown primary site & $13(0.9 \%)$ & & & & & & \\
\hline SEER stage, N (\%) & & & & $<0.0001$ & & & $<0.0001$ \\
\hline In Situ & $9(0.6 \%)$ & $5(0.7 \%)$ & $4(0.6 \%)$ & & $3(0.6 \%)$ & $6(0.7 \%)$ & \\
\hline Localized & $111(7.9 \%)$ & $74(10.3 \%)$ & $37(5.3 \%)$ & & $55(11.1 \%)$ & $56(6.1 \%)$ & \\
\hline Regional & $275(19.5 \%)$ & $170(23.6 \%)$ & $105(15.3 \%)$ & & $124(25.1 \%)$ & $151(16.5 \%)$ & \\
\hline Distant & $458(32.5 \%)$ & $193(26.8 \%)$ & $265(38.5 \%)$ & & $123(25 \%)$ & $335(36.7 \%)$ & \\
\hline Unknown (Unstaged) & $38(2.7 \%)$ & $16(2.2 \%)$ & $22(3.2 \%)$ & & $6(1.2 \%)$ & $32(3.5 \%)$ & \\
\hline Not applicable & $453(32.2 \%)$ & $229(31.8 \%)$ & $224(32.6 \%)$ & & $163(33.0 \%)$ & $290(31.7 \%)$ & \\
\hline Not available & $64(4.5 \%)$ & $33(4.6 \%)$ & $31(4.5 \%)$ & & $20(4 \%)$ & $44(4.8 \%)$ & \\
\hline Recent Chemotherapy, N (\%) & & & & 0.921 & & & 0.19771 \\
\hline Yes & $402(28.6 \%)$ & $206(28.6 \%)$ & $196(28.5 \%)$ & & $151(30.7 \%)$ & $251(27.5 \%)$ & \\
\hline No & 999 (71\%) & 509 (71.2\%) & $490(71.2 \%)$ & & $339(68.6 \%)$ & $660(72.2 \%)$ & \\
\hline No available data & $7(0.4 \%)$ & $5(0.2 \%)$ & $2(0.3 \%)$ & & $4(0.7 \%)$ & $3(0.3 \%)$ & \\
\hline Smoking, N (\%) & & & & 0.37882 & & & 0.0191 \\
\hline Yes & $631(44.8 \%)$ & $330(45.8 \%)$ & $301(43.8 \%)$ & & $242(49 \%)$ & $389(42.6 \%)$ & \\
\hline Not available & $117(8.3 \%)$ & $61(8.5 \%)$ & $56(8.1 \%)$ & & $40(8.1 \%)$ & $77(8.4 \%)$ & \\
\hline Neutropenia, N (\%) & $272(19.3 \%)$ & $142(19.7 \%)$ & $130(18.9 \%)$ & 0.69443 & $106(21.5 \%)$ & $166(18.2 \%)$ & 0.13496 \\
\hline Thrombocytopenia, N (\%) & $556(39.5 \%)$ & $244(33.9 \%)$ & $312(45.3 \%)$ & 0.00001 & 157 (31.8\%) & 399 (43.7\%) & 0.00001 \\
\hline Mechanical ventilation, $\mathrm{N}(\%)$ & $591(42 \%)$ & $230(31.9 \%)$ & $361(52.5 \%)$ & $<0.0001$ & 138 (27.9\%) & $453(49.6 \%)$ & $<0.0001$ \\
\hline Positive cultures, N (\%) & $836(59.4 \%)$ & $380(52.8 \%)$ & $456(66.3 \%)$ & $<0.0001$ & $247(50 \%)$ & $589(64.4 \%)$ & $<0.0001$ \\
\hline Acute kidney injury, N (\%) & & & & 0.37852 & & & 0.38032 \\
\hline Yes & $579(41.1 \%)$ & $323(44.9 \%)$ & $256(37.2 \%)$ & & $228(46.1 \%)$ & $351(38.4 \%)$ & \\
\hline No & $551(39.1 \%)$ & $293(40.1 \%)$ & $258(37.5 \%)$ & & $203(41.1 \%)$ & $348(38.1 \%)$ & \\
\hline Not available & 278 (19.8\%) & 104 (15\%) & 174 (25.3\%) & & 63 (12.8\%) & 215 (23.5\%) & \\
\hline
\end{tabular}


Table 1 Baseline characteristics and univariate analysis (Continued)

\begin{tabular}{|c|c|c|c|c|c|c|c|}
\hline \multirow[t]{2}{*}{ Baseline characteristic } & \multirow{2}{*}{$\begin{array}{l}\text { Value } \\
(N=1408)\end{array}$} & \multicolumn{2}{|c|}{ ICU mortality } & \multirow[t]{2}{*}{ P-value } & \multicolumn{2}{|c|}{ Hospital mortality } & \multirow[t]{2}{*}{$P$-value } \\
\hline & & Alive & Dead & & Alive & Dead & \\
\hline Elevated total bilirubin level mg/dl, N (\%) & & & & 0.00009 & & & 0.00004 \\
\hline Yes & $195(13.8 \%)$ & $80(11.1 \%)$ & $115(16.7 \%)$ & & $49(9.9 \%)$ & $146(16 \%)$ & \\
\hline No & $875(62.2 \%)$ & $494(68.6 \%)$ & $381(55.4 \%)$ & & $359(72.7 \%)$ & $516(56.5 \%)$ & \\
\hline Not available & $338(24 \%)$ & $146(20.3 \%)$ & $192(27.9 \%)$ & & $86(17.4 \%)$ & $252(27.5 \%)$ & \\
\hline Elevated lactic acid level mmol/l, $\mathrm{N}(\%)$ & & & & 0.00164 & & & 0.00017 \\
\hline Yes & $918(65.2 \%)$ & $437(60.7 \%)$ & $481(69.9 \%)$ & & $284(57.5 \%)$ & $634(69.4 \%)$ & \\
\hline No & $370(26.3 \%)$ & $212(29.4 \%)$ & $158(23 \%)$ & & $155(31.4 \%)$ & $215(23.5 \%)$ & \\
\hline Not available & $120(8.5 \%)$ & 71 (9.9\%) & $49(7.1 \%)$ & & 55 (11.1\%) & 65 (7.1\%) & \\
\hline
\end{tabular}

16.1 (SD) years and mean APACHE II score was $23.0 \pm$ 7.91 (SD). The majority of the included patients had solid malignancies (67.8\%) and 402 (28.6\%) received chemotherapy within 1 month prior to the ICU admission. Neutropenia and thrombocytopenia were reported in 19.3 and $39.5 \%$ of the patients, respectively, and mechanical ventilation was required for $42 \%$ of the patients. Acute kidney injury was reported upon ICU admission in $579(41.1 \%)$ of the patients. Elevated total bilirubin level was reported in 195 (13.8\%) and elevated lactic acid level was reported in 918 (65.2\%) patients.

Positive cultures were reported in 836 (59.4\%) patients, most commonly blood and respiratory, with approximately two-third of the cultures being Gram-negative pathogens (Table 2). The median ICU length of stay was 4 days (IQR 3-8) and the ICU and hospital mortality were reported in 688 (48.9\%) and 914 (64.9\%) patients, respectively.

In the logistic regression analysis of factors that were significant in the univariate analysis (Table 1), mechanical ventilation, thrombocytopenia, elevated total bilirubin, elevated lactic acid levels, presence of positive cultures and Apache II score within the first $24 \mathrm{~h}$ of admission were significantly associated with both ICU and hospital mortality as presented in Table 3.

\section{Discussion}

In this report, we described the outcomes of a large cohort of patients with solid and hematological malignancies admitted to the ICU with septic shock. In addition, we evaluated predictors of mortality in this patient population. In our 12-year study, about two-third of the patients treated for septic shock died during their hospitalization. Though the mortality rate reported in this study may be comparable to the outcomes reported by others for cancer patients with septic shock $[16,19]$, the high mortality rate highlights the importance of identifying measures to improve the outcomes in cancer patients with septic shock as well as developing prediction models to help in the early identification of patients with poor prognosis. We identified several factors associated with hospital mortality, with mechanical ventilation and elevated bilirubin levels having the highest association. Other factors were the APACHE II, thrombocytopenia, elevated lactic acid levels, and the presence of positive cultures.

De Montmollin et al. [16] evaluated the outcomes of 218 critically ill cancer patients with septic shock of

Table 2 Type of cultures and microorganisms

\begin{tabular}{ll}
\hline Type of positive culture/microorganism & $\mathbf{N}(\%)$ \\
\hline Type of positive culture*, N & $\mathbf{1 1 1 6 ( 1 0 0 \% )}$ \\
Blood culture & $368(33 \%)$ \\
Trap culture & $297(26.6 \%)$ \\
Urine culture & $179(16.1 \%)$ \\
Wound culture & $132(11.8 \%)$ \\
Others & $140(12.5 \%)$
\end{tabular}

Type of microorganisms ${ }^{a}$

Gram negative bacteria $\quad 768(68.8 \%)$

$\begin{array}{ll}\text { Escherichia coli } & 269(35 \%) \\ \text { Klebsiella pneumoniae } & 129(16.8 \%) \\ \text { Pseudomonas aeruginosa } & 125(16.3 \%) \\ \text { Acinetobacter baumannii } & 110(14.3 \%) \\ \text { Others } & 135(17.5 \%) \\ \text { Gram positive bacteria } & \mathbf{4 2 1 ( 3 7 . 7 \% )} \\ \text { Staphylococcus aureus } & 142(33.7 \%) \\ \text { Coagulase-negative staphylococci } & 72(17.1 \%) \\ \text { Enterococcus species } & 65(15.4 \%) \\ \text { Streptococcus species } & 31(7.4 \%) \\ \text { Corynebacterium species } & 15(3.6 \%) \\ \text { Others } & 96(22.8 \%) \\ \text { Fungal } & \mathbf{1 4 7}(\mathbf{1 3 . 1 \% )} \\ \text { Candida species } & 130(88.4 \%) \\ \text { Aspergillus } & 17(11.6 \%)\end{array}$

${ }^{a}$ Eight hundred thirty-six patients had microbiologically proven infection; with a total of 1116 reported positive culture as patients could have more than one culture. Also, patients could have had more than one pathogen type in each culture type 
Table 3 Predictors significantly associated with mortality

\begin{tabular}{|c|c|c|c|c|}
\hline \multirow{2}{*}{$\frac{\text { Predictor }}{\text { ICU mortality }}$} & \multirow[t]{2}{*}{ Odds Ratio } & \multicolumn{2}{|c|}{ 95\% Confidence Limits } & \multirow[t]{2}{*}{$P$-value } \\
\hline & & & & \\
\hline Mechanical ventilation & 2.109 & 1.682 & 2.643 & $<.0001$ \\
\hline Apache II score & 1.054 & 1.039 & 1.069 & $<.0001$ \\
\hline Thrombocytopenia & 1.611 & 1.285 & 2.020 & $<.0001$ \\
\hline Positive culture & 1.632 & 1.301 & 2.048 & $<.0001$ \\
\hline Elevated total bilirubin level & 1.940 & 1.366 & 2.757 & 0.0002 \\
\hline Elevated lactic acid level & 1.355 & 1.009 & 1.820 & 0.0436 \\
\hline \multicolumn{5}{|l|}{ Hospital mortality } \\
\hline Mechanical ventilation & 2.224 & 1.740 & 2.844 & $<.0001$ \\
\hline Apache II score & 1.063 & 1.046 & 1.080 & $<.0001$ \\
\hline Thrombocytopenia & 1.640 & 1.287 & 2.089 & $<.0001$ \\
\hline Positive culture & 1.652 & 1.305 & 2.090 & $<.0001$ \\
\hline Elevated total bilirubin level & 2.311 & 1.555 & 3.436 & $<.0001$ \\
\hline Elevated lactic acid level & 1.477 & 1.095 & 1.992 & 0.0106 \\
\hline
\end{tabular}

pulmonary origin. The study included patients with both solid and hematological malignancies, but unlike our study, the majority of their patients had hematological malignancies. Though the proportion of patients that required mechanical ventilation was higher than that reported in our study $(78.4 \%$ vs $42 \%)$, they described similar hospital mortality (62.4\%). However, De Montmollin et al. did not provide any mortality prediction scores (e.g., APACHE II) for their patients and therefore, it would be difficult to determine if the patients in both studies had similar severity of illnesses. In their study, hospital mortality was associated with age older than 60 years, time between first symptoms and ICU admission, mechanical ventilation, and coma.

Regazzoni et al. [19] evaluated the outcomes and predictors of mortality in a group of 73 patients with cancer and septic shock. Though more patients required mechanical ventilation, compared to our study $(61.6 \%$ vs $42 \%$ ), the mean APACHE II was lower (21.5 vs 23 ). ICU mortality was reported in $53.4 \%$ of the patients and the need for mechanical ventilation and liver dysfunction were independent predictors of mortality. However, the APACHE II score was not identified as a significant mortality predictor.

Several other studies evaluated septic shock in cancer patients, but they included patients with sepsis and septic shock, with the proportion of septic shock patients ranging between 25 and $60 \%$ of the study population [4, $7,13-19,21,23,24]$. Lemiale et al. [23] recently published the characteristics and outcomes of a large cohort of cancer patients treated with sepsis and septic shock at 7 European ICUs over two decades (1994-2015). Among the enrolled patients, $56.8 \%$ received vasopressors, $49.3 \%$ required mechanical ventilation, and the majority had hematological malignancies. The study reported a day30 mortality in $39.9 \%$ of the patients and identified mechanical ventilation and vasopressors use as independent factors associated with mortality.

Thrombocytopenia upon admission was associated with increased ICU and hospital mortality in this study. Few studies evaluated the impact of thrombocytopenia on the outcomes of critically ill patients. Williamson et al. [25] reported that thrombocytopenia upon admission was independently associated with mortality, with the greatest impact in patients with certain conditions, one of which was cancer. In addition, Burunsuzoğlu et al. [24] reported a higher ICU mortality rate in those who developed thrombocytopenia during ICU admission in comparison to those who did not (40.3\% versus $17.5 \%)$.

Despite the assumption that neutropenia may impact the outcomes of patients with serious infections, recent data has suggested otherwise. In our study, neutropenia was not identified as a significant predictor of mortality. In a meta-analysis conducted by Bouteloup et al. [26], though the unadjusted mortality of neutropenic patients with cancer was $11 \%$ higher, compared to nonneutropenic patients, this effect was not significant when adjusted for severity of illness. Similar observations were also reported by Regazzoni et al. in which neutropenia did not impact the outcomes of cancer patients with septic shock [19].

Data regarding the impact of total bilirubin level on mortality is limited. In our study, the presence of elevated total bilirubin level was associated with both ICU and hospital mortality. Namendys-Silva et al. [14] also reported that total bilirubin level is one of the predictors for organ failure that is associated with ICU mortality. On the other hand, Regazzoni et al. [19] did not find a 
significant association between liver dysfunction and mortality.

Similar to what was reported earlier by Hawari et al. [3] in cancer patients, our study showed that elevated lactic acid level within $24 \mathrm{~h}$ of ICU admission with septic shock was a predictor for mortality. Data evaluating the association between elevated lactic acid and mortality varied. One study [27] reported lactic acid as an independent factor to predict mortality in cancer patients admitted with sepsis, while another study concluded that lactic acid alone is insufficient to predict poor outcomes in this patient population [28].

The association between renal failure and increased mortality in critically ill cancer patients was reported in several studies either in the form of severe renal impairment that necessitated renal replacement therapy [23, $29,30]$ or acute kidney injury despite the severity level [17]. In our study; acute kidney injury was not identified as a significant predictor of mortality; this could be related to the criteria we used to define acute kidney injury and the inability to distinguish those who needed renal replacement therapy. Lemiale et al. [23] published a large cohort study of cancer patients treated with sepsis and septic shock in which renal replacement therapy, but not acute kidney injury, was associated with poor outcomes.

In this study, the presence of positive cultures was identified as a predictor associated with both ICU and hospital mortality. Sigakis et al. [31] evaluated the outcomes of culture-negative and culture-positive sepsis in a large cohort of patients from the intensive care units, emergency department, and general wards. After adjusting for severity of illness, the authors reported no difference in outcomes between the two groups. In a study conducted by Azoulay et al. [4], similar findings were reported in patients with cancer, in which positive cultures were not associated with mortality. We hypothesis that the differences in findings may be related to the type of infections and the time to initiating antibiotics, especially in patients with multi-drug resistant Gram-negative pathogens. We previously reported higher mortality in patients with multi-drug resistant Acinetobacter baumannii who had appropriate antimicrobial therapy (i.e., colistin) initiated after $24 \mathrm{~h}$ of onset of sepsis [32]. Given that Gram-negative infections were the most common infection in our patients, and that cancer patients are at risk of infections with multi-drug resistant pathogens, the timing for initiating appropriate antibiotics may have contributed to this finding. However, this will need to be further explored to future studies.

This study has several limitations which we would like to highlight. The first related to the retrospective nature of the study which may have limited out ability to extract some of the necessary findings for patients with septic shock, such certain patient-related and infectionrelated features. In addition, we did not evaluate the goals of care and code status of patients during their ICU stay, which are factors that may impact the mortality outcome of patients. Furthermore, though we evaluated lactic acid upon admission, we did evaluate all subsequent lactic acid measurements and their impact of mortality. However, in an earlier study, we evaluated the predictive value of lactate in cancer patients with septic shock [33]. In the study, though normalization of lactate and clearance at $24 \mathrm{~h}$ were predictors of hospital mortality, they were not found to be strong predictors. Another limitation was being single centered and therefore, further multi-center studies are necessary to evaluate the outcomes of septic shock in cancer patients.

\section{Conclusions}

In a relatively large cohort of patients with solid and hematological malignancies admitted to the ICU with septic shock, about two-third of the patients died prior to hospital discharge. Mechanical ventilation, APACHE II, thrombocytopenia, positive cultures, and elevated bilirubin and lactic acid levels were significant predictors of mortality. Future studies should identify measures to improve the outcomes of this patient population and to develop predictive models to identify patients with cancer and septic shock who may have poor outcomes.

\section{Abbreviations \\ ICU: Intensive Care Unit; ANC: Absolute Neutrophils Count; APACHE II \\ score: Acute Physiology and Chronic Health Evaluation II score; \\ SEER: Surveillance Epidemiology and End Results}

\section{Acknowledgements}

The authors thank Heba Al-Saghayer, Data Manger of the intensive care unit at King Hussein Cancer Center, for her assistance in obtaining the data from the ICU electronic database.

\section{Authors' contributions}

WA, LN and FH developed the research question and the research protocol. WA, LN, SE and MA were involved in data collection. All authors were involved in data analysis, interpretation of the results, and manuscript writing, and all have reviewed and approved the final manuscript.

\section{Funding}

Not applicable.

\section{Availability of data and materials}

The datasets used and/or analyzed during the current study are available from the corresponding author on reasonable request.

\section{Declarations}

Ethics approval and consent to participate

The study protocol was approved by the Institutional Review Board of King Hussein Cancer Center under the reference number of 20KHCC109, and the Institutional Review Board granted the waiver for the informed consent, the permission to access the raw data and patients' electronic medical records. The data were coded and anonymized before analysis. The study followed the relevant guidelines and regulations of both good clinical practice guidelines and our Institutional Review Board. 


\section{Consent for publication}

Not applicable.

\section{Competing interests}

The authors declare that they have no competing interests.

\section{Author details}

'Department of Pharmacy, King Hussein Cancer Center, P.O. Box 1269, Al-Jubeiha, Amman 11941, Jordan. ${ }^{2}$ Department of Medicine, King Hussein Cancer Center, Amman, Jordan.

Received: 10 February 2021 Accepted: 1 June 2021 Published online: 16 June 2021

\section{References}

1. Williams MD, Braun LA, Cooper LM, Johnston J, Weiss RV, Qualy RL, et al. Hospitalized cancer patients with severe sepsis: analysis of incidence, mortality, and associated costs of care. Crit Care. 2004;8:291-8.

2. Hensley MK, Donnelly JP, Carlton EF, Prescott HC. Epidemiology and outcomes of cancer-related versus non-cancer-related sepsis hospitalizations. Crit Care Med. 2019;47(10):1310-6. https://doi.org/10.1097/ CCM.0000000000003896.

3. Hawari Fl, Nazer LH, Addassi A, Rimawi D, Jamal K. Predictors of ICU admission in patients with cancer and the related characteristics and outcomes: a 5-year registry-based study. Crit Care Med. 2016;44(3):548-33. https://doi.org/10.1097/CCM.0000000000001429.

4. Azoulay E, Mokart D, Pène F, Lambert J, Kouatchet A, Mayaux J, et al. Outcomes of critically ill patients with hematologic malignancies: prospective multicenter data from France and Belgium--a groupe de recherche respiratoire en réanimation onco-hématologique study. J Clin Oncol. 2013;31(22):2810-8. https://doi.org/10.1200/JCO.2012.47.2365.

5. Soares M, Caruso P, Silva E, Teles JM, Lobo SM, Friedman G, et al. Brazilian research in intensive care (BRICNet). Characteristics and outcomes of patients with cancer requiring admission to intensive care units: a prospective multicenter study. Crit Care Med. 2010;38(1):9-15. https://doi. org/10.1097/CCM.0b013e3181c0349e.

6. Moore JX, Akinyemiju T, Bartolucci A, Wang HE, Waterbor J, Griffin R. A prospective study of cancer survivors and risk of sepsis within the REGARDS cohort. Cancer Epidemiol. 2018;55:30-8. https://doi.org/10.1016/j.canep.2018.05.001.

7. Wang YG, Zhou JC, Wu KS. High 28-day mortality in critically ill patients with sepsis and concomitant active cancer. J Int Med Res. 2018;46(12):50309. https://doi.org/10.1177/0300060518789040.

8. Danai RA, Moss M, Mannino DM, Martin GS. The epidemiology of sepsis in patients with malignancy. Chest. 2006;129(6):1432-40. https://doi.org/10.13 78/chest.129.6.1432.

9. Sauer CM, Dong J, Celi LA, Ramazzotti D. Improved survival of Cancer patients admitted to the intensive care unit between 2002 and 2011 at a U. S. teaching hospital. Cancer Res Treat. 2019;51(3):973-81. https://doi.org/1 0.4143/crt.2018.360.

10. Ostermann M, Ferrando-Vivas P, Gore C, Power S, Harrison D. Characteristics and outcome of Cancer patients admitted to the ICU in England, Wales, and Northern Ireland and National Trends between 1997 and 2013. Crit Care Med. 2017:45(10):1668-76. https://doi.org/10.1097/CCM.0000000000002589.

11. Tolsma V, Schwebel C, Azoulay E, Darmon M, Souweine B, Vesin A, et al. Sepsis severe or septic shock: outcome according to immune status and immunodeficiency profile. Chest. 2014;146(5):1205-13. https://doi.org/10.13 78/chest.13-2618.

12. Cecconi M, Evans L, Levy M, Rhodes A. Sepsis and septic shock. Lancet. 2018;392(10141):75-87.

13. Vincent F, Soares M, Mokart D, Lemiale V, Bruneel F, Boubaya M, et al. Inhospital and day-120 survival of critically ill solid cancer patients after discharge of the intensive care units: results of a retrospective multicenter study-a Groupe de recherche respiratoire en réanimation en OncoHématologie (Grrr-OH) study. Ann Intensive Care. 2018;8(1):40. https://doi. org/10.1186/s13613-018-0386-6

14. Ñamendys-Silva SA, Barragán-Dessavre M, Bautista-Ocampo AR, García-Guillén FJ, Córdova-Sánchez BM, Constantino-Hérnandez E, et al. Outcome of critically ill patients with testicular Cancer. Biomed Res Int. 2017;2017:3702605.

15. Torres VB, Azevedo LC, Silva UV, Caruso P, Torelly AP, Silva E, et al. Sepsisassociated outcomes in critically ill patients with malignancies. Ann Am Thorac Soc. 2015;12(8):1185-92. https://doi.org/10.1513/AnnalsATS.201501-0460C.
16. De Montmollin E, Tandjaoui-Lambiotte $\mathrm{Y}$, Legrand M, Lambert J, Mokart $\mathrm{D}$, Kouatchet A, et al. Outcomes in critically ill cancer patients with septic shock of pulmonary origin. Shock. 2013;39(3):250-4. https://doi.org/10.1097/ SHK.0b013e3182866d32.

17. Rosolem MM, Rabello LS, Lisboa T, Caruso P, Costa RT, Leal JV, et al. Critically ill patients with cancer and sepsis: clinical course and prognostic factors. J Crit Care. 2012;27(3):301-7. https://doi.org/10.1016/j.jcrc.2011.06.014.

18. Taccone FS, Artigas AA, Sprung CL, Moreno R, Sakr Y, Vincent JL. Characteristics and outcomes of cancer patients in European ICUs. Crit Care. 2009;13:15.

19. Regazzoni CJ, Irrazabal C, Luna CM, Poderoso JJ. Cancer patients with septic shock: mortality predictors and neutropenia. Support Care Cancer. 2004; 12(12):833-9. https://doi.org/10.1007/s00520-004-0667-5.

20. Biard L, Darmon M, Lemiale V, Mokart D, Chevret S, Azoulay E, et al. Center effects in hospital mortality of critically ill patients with hematologic malignancies. Crit Care Med. 2019;47(6):809-16. https://doi.org/10.1097/ CCM.0000000000003717.

21. Legrand M, Max A, Peigne V, Mariotte E, Canet E, Debrumetz A, et al. Survival in neutropenic patients with severe sepsis or septic shock. Crit Care Med. 2012;40(1):43-9. https://doi.org/10.1097/CCM.0b013e31822b50c2.

22. Rhodes A, Evans LE, Alhazzani W, Levy MM, Antonelli M, Ferrer R, et al. Surviving Sepsis campaign: international guidelines for Management of Sepsis and Septic Shock: 2016. Intensive Care Med. 2017;43(3):304-77. https://doi.org/10.1007/s00134-017-4683-6.

23. Lemiale V, Pons S, Mirouse A, Tudesq JJ, Hourmant Y, Mokart D, et al. Sepsis and septic shock in patients with malignancies: a Groupe de Recherche Respiratoire en Réanimation Onco-Hématologique study. Crit Care Med. 2020;48(6):822-9. https://doi.org/10.1097/CCM.0000000000004322.

24. Burunsuzoğlu B, Saltürk C, Karakurt Z, Öngel EA, Takır HB, Kargin F, et al. Thrombocytopenia: a risk factor of mortality for patients with Sepsis in the intensive care unit. Turk Thorac J. 2016;17(1):7-14. https://doi.org/10.5578/tti.17.1.002.

25. Williamson DR, Lesur O, Tétrault JP, Nault V, Pilon D. Thrombocytopenia in the critically ill: prevalence, incidence, risk factors, and clinical outcomes. Can J Anaesth. 2013;60(7):641-51. https://doi.org/10.1007/s12630-013-9933-7.

26. Bouteloup M, Perinel S, Bourmaud A, Azoulay E, Mokart D, Darmon M, et al. Outcomes in adult critically ill cancer patients with and without neutropenia: a systematic review and meta-analysis of the Groupe de Recherche en Réanimation Respiratoire du patient d'Onco-Hématologie (GRRR-OH). Oncotarget. 2017;8(1):186070. https://doi.org/10.18632/oncotarget.12165.

27. Hajjar LA, Nakamura RE, de Almeida JP, Fukushima JT, Hoff PM, Vincent JL, et al. Lactate and base deficit are predictors of mortality in critically ill patients with cancer. Clinics. 2011;66(12):2037-42. https://doi.org/10.1590/S1 807-59322011001200007.

28. Kece E, Yaka E, Yilmaz S, Dogan NO, Alyesil C, Pekdemir M. Comparison of diagnostic and prognostic utility of lactate and procalcitonin for sepsis in adult cancer patients presenting to emergency department with systemic inflammatory response syndrome. Turk J Emerg Med. 2016;16(12):1-7. https://doi.org/10.1016/j.tjem.2016.02.003.

29. Georges Q, Azoulay E, Mokart D, Soares M, Jeon K, Oeyen S, et al. Influence of neutropenia on mortality of critically ill cancer patients: results of a metaanalysis on individual data. Crit Care. 2018;22(1):326. https://doi.org/10.1186/ s13054-018-2076-Z.

30. Faucher E, Cour M, Jahandiez V, Grateau A, Baudry T, Hernu R, et al. Shortand long-term outcomes in onco-hematological patients admitted to the intensive care unit with classic factors of poor prognosis. Oncotarget. 2016; 7(16):22427-38. https://doi.org/10.18632/oncotarget.7986.

31. Sigakis MJG, Jewell E, Maile MD, Cinti SK, Bateman BT, Engoren M. Culturenegative and culture-positive sepsis: a comparison of characteristics and outcomes. Anesth Analg. 2019;129(5):1300-9. https://doi.org/10.1213/ANE. 0000000000004072.

32. Nazer LH, Kharabsheh A, Rimawi D, Mubarak S, Hawari F. Characteristics and outcomes of Acinetobacter baumannii infections in critically ill patients with Cancer: a matched case-control study. Microb Drug Resist. 2015;21(5):55661. https://doi.org/10.1089/mdr.2015.0032.

33. Nazer $\mathrm{LH}$, Rimawi $\mathrm{D}$, Hawari Fl. Evaluating the predictive value of lactate in patients with Cancer having septic shock. J Intensive Care Med. 2020;35(8): 789-96. https://doi.org/10.1177/0885066618788821.

\section{Publisher's Note}

Springer Nature remains neutral with regard to jurisdictional claims in published maps and institutional affiliations. 